\title{
Polymorphs of $\mathrm{Rb}_{3} \mathrm{ScF}_{6}$ : X-ray and neutron diffraction, solid- state NMR, and DFT calculations study
}

Aydar Rakhmatullin ${ }^{* \dagger}$, Maxim S. Molokeev ${ }^{,+,}$, , Graham King ${ }^{\diamond}$, Ilya B. Polovov ${ }^{\S}$, Konstantin V. Maksimtsev ${ }^{\S}$, Erwan Chesneau ${ }^{\dagger}$, Emmanuelle Suard ${ }^{\nabla}$, Rinat Bakirov", František Šimko ${ }^{\#, \square,}$ Catherine Bessada ${ }^{\dagger}$, and Mathieu Allix ${ }^{\dagger}$

${ }^{\dagger}$ Conditions Extrêmes et Matériaux: Haute Température et Irradiation, CEMHTI, UPR 3079 CNRS Univ. Orléans 45071, Orléans, France.

$\$$ Laboratory of Crystal Physics, Kirensky Institute of Physics, Federal Research Center KSC SB RAS, Krasnoyarsk 660036, Russia

$\perp$ Siberian Federal University, Krasnoyarsk 660041, Russia

${ }^{\diamond}$ Material and Chemical Sciences, Canadian Light Source, 44 Innovation Blvd, Saskatoon, SK S7N 2V3, Canada

$\S$ Department of Rare Metals and Nanomaterials, Institute of Physics and Technology Ural Federal University, 19, Mira str. 620002 Ekaterinburg, Russia

$\nabla$ Institut Laue-Langevin, F-38042 Grenoble 9, France

॥ Department of Technology of mechanical engineering and instrument making, Votkinsk branch of Kalashnikov Izhevsk State Technical University, 1, Shuvalova str. 427000 Votkinsk, Russia

\# Institute of Inorganic Chemistry, Slovak Academy of Sciences, Dúbravská cesta 9, 84536 Bratislava, Slovakia

Centre of Excellence for advanced Materials Application - CEMEA, Slovak Academy of Sciences, Dúbravská cesta 5807/9, 84511 Bratislava, Slovakia

* Corresponding authors: Aydar Rakhmatullin, e-mail: rakhmat@cnrs-orleans.fr , tel.: +33 2382555 12, fax: +33238638103 


\begin{abstract}
The crystal structures of three polymorphs of $\mathrm{Rb}_{3} \mathrm{ScF}_{6}$ have been determined through a combination of synchrotron, laboratory X-ray, and neutron powder diffraction; electron diffraction; and multinuclear high field solid state NMR studies. The room temperature $(\alpha)$ and medium-temperature $(\beta)$ structures are tetragonal, with space groups $I 4_{1} / a(Z=80)$ and $I 4 / m(\mathrm{Z}=10)$, and lattice parameters $a=20.2561(4) \AA, c=36.5160(0) \AA$ and $a=14.4093(2)$ $\AA, c=9.2015(1) \AA$ at $\mathrm{RT}$ and $187{ }^{\circ} \mathrm{C}$, respectively. The high-temperature $(\gamma)$ structure is cubic, space group $F m \overline{3} m(\mathrm{Z}=4)$ with $a=9.1944(1) \AA$ at $250{ }^{\circ} \mathrm{C}$. The temperatures of the phase transitions were measured at $141{ }^{\circ} \mathrm{C}$ and $201{ }^{\circ} \mathrm{C}$. The three $\alpha, \beta$, and $\gamma \mathrm{Rb}_{3} \mathrm{ScF}_{6}$ phases are isostructural with the $\alpha$-, $\beta$-, and $\delta$-forms of the potassium cryolite. ${ }^{1,2}$ Detailed structural characterizations were performed by density functional theory (DFT) as well as NMR. In the case of the $\beta$ polymorph, the dynamic rotations of the $\mathrm{ScF}_{6}$ octahedra of both scandium crystallographic sites have been detailed.
\end{abstract}

Keywords: $\mathrm{Rb}_{3} \mathrm{ScF}_{6}$, phase transitions, in-situ high- temperature solid-state NMR, synchrotron X-ray powder diffraction, neutron powder diffraction; structure determination, DFT-GIPAW

\title{
Introduction
}

Alkali metal fluoroscandates have recently attracted much attention due to their promising potential use in many areas such as fluorescent probes, solar cell, solid-state lasers, and other fields. ${ }^{3-7}$ Due to their specific electronic configurations and the small ionic radius of scandium compared to other rare earth elements, fluoroscandates doped with $\mathrm{Mn}^{4+}$ or $\mathrm{Ln}^{3+}$ can generate interesting optical properties as recently demonstrated for $\mathrm{NaScF}_{4},{ }^{3,4} \mathrm{KSc}_{2} \mathrm{~F}_{7},{ }^{5,8}$ and $\mathrm{K}_{3} \mathrm{ScF}_{6}{ }^{9}$ $\mathrm{Mn}^{4+}$-doped $\mathrm{K}_{3} \mathrm{AlF}_{6}$ has been latterly reported to show high color rendering properties. ${ }^{10} \mathrm{As}$ recently demonstrated, $\mathrm{Rb}_{3} \mathrm{ScF}_{6}$ is isostructural with $\mathrm{K}_{3} \mathrm{AlF}_{6}{ }^{1,2}$ The specific crystal symmetry of the polymorphs, phase transitions, and associated physical properties of studied compound may be related to structural particularities of this class of compounds, which is named halide double perovskites $\left(\mathrm{A}_{2} \mathrm{BB}^{\prime} \mathrm{X}_{6}\right)$. The double perovskite structure is so-called because the unit cell of double perovskite is twice as large as that of a simple $\mathrm{ABX}_{3}$ perovskite. Moreover, $\mathrm{K}_{3} \mathrm{AlF}_{6}$ exhibits superstructure polymorphs, which was attributed to the non-cooperative 
octahedral tilting. ${ }^{1,2}$ Such structures are highly complex and difficult to study. Additionally, the dynamic motion of the $\mathrm{AlF}_{6}$ octahedra in $\mathrm{K}_{3} \mathrm{AlF}_{6}$ was established. An exact knowledge of the structure and dynamics of these various crystalline materials is required to understand their functionalities, and to further improve their properties to suit the above mentioned applications.

Structural studies on almost all reported lithium, potassium, and sodium fluoroscandates have been performed. Recently, the structure of two members of the $\mathrm{CsF}_{-} \mathrm{ScF}_{3}$ system, $\mathrm{CsScF}_{4}$ and $\mathrm{CsSc}_{3} \mathrm{~F}_{10}$, has been reported. ${ }^{11,12}$ However, rubidium containing fluoride compounds have been overlooked. Only the structure of the $\mathrm{RT} \mathrm{RbSc}_{3} \mathrm{~F}_{10}$ polymorph has been reported to date. It is worth noting that this study was only published in a $\mathrm{PhD}$ manuscript and is not included in structural databases. ${ }^{13}$ Regarding $\mathrm{Rb}_{3} \mathrm{ScF}_{6}$, Turrell et al. ${ }^{14}$ found that the compound undergoes two polymorphic transformations at $154{ }^{\circ} \mathrm{C}$ and $200{ }^{\circ} \mathrm{C}$. From X-ray powder diffraction data, it was proposed that the room temperature and medium-temperature structures are tetragonal, with space group $P 4 / m n c(\mathrm{Z}=128)$ at $\mathrm{RT}$ and the lattice parameters $a=6.419 \AA, c=9.154 \AA$ and $a=6.467 \AA, c=9.222 \AA$ at $\mathrm{RT}$ and $177^{\circ} \mathrm{C}$, respectively. The high-temperature structure was reported to be cubic, space group $F m \overline{3} m(\mathrm{Z}=4)$ with $a=$ $9.214 \AA$ at $250{ }^{\circ} \mathrm{C}$. From variable temperature Raman spectroscopy experiments, the authors stated that all polymorphs contain isolated $\mathrm{ScF}_{6}{ }^{3-}$ octahedra. However, only cell parameters and space groups were proposed for the three polymorphs and the crystalline structures have not been established.

In this paper, we used a combined approach including solid state NMR spectroscopy, transmission electron microscopy, and synchrotron, neutron powder diffraction to precisely determine the structure of three $\mathrm{Rb}_{3} \mathrm{ScF}_{6}$ polymorphs between $\mathrm{RT}$ and high temperature. In addition, we employed in-situ high- temperature (HT) MAS NMR experiments to follow the structural transitions and dynamics. 2D MQMAS NMR methods enabled to enhance the spectral resolution by spreading signals in two spectral dimensions. High- temperature MAS NMR is an unusual method for structural characterization. Here, we show that the use of this technique can provide an accurate description of the phase transitions, as well as quantitative and qualitative information on structure and dynamics.

\section{EXPERIMENTAL}

Synthesis 
Rubidium fluoride (Aldrich, $99.8 \%$ ) and scandium fluoride (JSC Dalur, >99 \%) powder precursors were used for the synthesis of $\mathrm{Rb}_{3} \mathrm{ScF}_{6}$. The salts were first dried under vacuum at $150{ }^{\circ} \mathrm{C}$ for $6 \mathrm{~h}$ and then transferred to an argon filled glovebox. All the manipulations were performed in an argon-filled glovebox, unless mentioned otherwise. Both salts were then mixed and homogenized in an agate mortar in required proportions (5 grams of mixture; $3.7727 \mathrm{~g}$ of $\mathrm{RbF}$ and $1.2273 \mathrm{~g}$ of $\mathrm{ScF}_{3}$ ) and placed into a nickel crucible covered with nickel lid. The synthesis was performed by solid state reaction inside the glovebox to exclude possible contamination by moisture and minimize the influence of oxygen. The crucibles were placed in the furnace, and the heating was performed at $840{ }^{\circ} \mathrm{C}$ for $6 \mathrm{~h}$ with a heating rate of $5{ }^{\circ} \mathrm{C} / \mathrm{min}$. The furnace was then cooled with a rate of $2{ }^{\circ} \mathrm{C} / \mathrm{min}$, and the crucibles were taken out and weighed. The changes of crucible's mass did not exceed $10 \mathrm{mg}$, and vapor deposition was not noticed. The resulting pale-white salt was extracted from the crucible outside the glovebox and homogenized.

\section{Thermal analysis measurements}

Differential scanning calorimetry (DSC) was used for following phase transformations taking place during both heating and cooling of $\mathrm{Rb}_{3} \mathrm{ScF}_{6}$. The measurements were performed with a Mettler Toledo STAR DSC823 calorimeter equipped with a FRS 5 sensor and $56 \mathrm{Au}$ $\mathrm{Au} / \mathrm{Pd}$ thermocouples (working range of $10-700{ }^{\circ} \mathrm{C}$, resolution $<0.04 \mu \mathrm{W}$ ). The $\mathrm{Rb}_{3} \mathrm{ScF}_{6}$ samples were loaded in a platinum crucibles and heated from 25 to $260{ }^{\circ} \mathrm{C}$ at 5 (heating) and $7{ }^{\circ} \mathrm{C} / \mathrm{min}$ (cooling). Dry air flow through the furnace was maintained at $50 \mathrm{ml} / \mathrm{s}$ rate.

\section{Electron diffraction}

Selected area electron diffraction (SAED) patterns were collected on a Philips CM20 transmission electron microscope (TEM) fitted with an Oxford energy dispersive spectrometry (EDS) analyzer. The sample was first crushed in ethanol, and then a drop of the solution with the small crystallites in suspension was deposited onto a carbon-coated copper grid.

\section{X-ray Powder Diffraction}

High resolution synchrotron powder diffraction data were collected at the 11-BM beamline at the Advanced Photon Source (APS), Argonne National Laboratory using a wavelength of $0.457893 \AA$ at RT and $0.457901 \AA$ at $187{ }^{\circ} \mathrm{C}$. The powder was packed into a 
kapton capillary with an outer diameter of $0.8 \mathrm{~mm}$ and spun during data acquisition from 0.5 to $50^{\circ}$ ( 2 theta) using $0.001^{\circ}$ steps.

High temperature X-Ray powder diffraction (XRPD) data were recorded on a Bragg Brentano D8 Advance Bruker diffractometer $\left(\mathrm{CuK}_{\alpha}\right.$ radiation) equipped with a LynxEye XE detector over an angular range of $5^{\circ}<2 \theta<130^{\circ}$.

Rietveld refinements were performed using the Topas $4.2^{15}$ and JANA2006 ${ }^{16}$ software.

\section{Neutron Powder Diffraction}

Neutron powder diffraction (NPD) data were obtained at the Institute Laue Langevin (ILL, Grenoble, France) on the D2B diffractometer at room temperature using an $8 \mathrm{~mm}$ diameter vanadium tube. Data were collected with a wavelength of $1.59354 \AA$ over a range of $0^{\circ}<2 \theta<160^{\circ}$ with a $0.05^{\circ}$ step size.

\section{NMR spectroscopy}

Room temperature solid-state MAS NMR spectra were recorded on a Bruker Avance III HD 17.6 and Avance NEO $20 \mathrm{~T}$ spectrometers using 1.3 and $2.5 \mathrm{~mm}$ resonance probes at MAS frequency of 60 or $30 \mathrm{kHz}$, respectively. ${ }^{19} \mathrm{~F},{ }^{45} \mathrm{Sc}$, and ${ }^{87} \mathrm{Rb} \mathrm{RF}$ strengths were 190, 464, and $83 \mathrm{kHz}$, respectively. ${ }^{87} \mathrm{Rb}$ MQMAS spectra were acquired by two different ways, i.e. either with Z-filtering ${ }^{17}$ and using RIACT excitation method. ${ }^{18}$ The Z-filter experiment parameters were identical to the ones used in our previous study. ${ }^{19}$ RIACT MQMAS spectra were measured using the two pulse RIACT (II) sequence ${ }^{20}$ with pulse widths of $3.7 \mu$ s and 8 $\mu \mathrm{s}$, at a RF field of $\sim 150 \mathrm{kHz}$. The sweep widths were $500 \mathrm{kHz}$ and $120 \mathrm{kHz}\left(4 v_{\mathrm{r}}\right)$ in the direct and indirect dimension. A recycle delay of $0.1 \mathrm{~s}$ has been used.

High temperature data were collected at 17.6 $\mathrm{T}$ using a MAS LASER probe with boron nitride crucibles contained in $7 \mathrm{~mm}$ zirconia bottom-less rotor spinning at $6 \mathrm{kHz}$. The diode laser beam (DILAS $200 \mathrm{~W}, 980 \mathrm{~nm}$ ) is guided by fiber optics to the crucible. Unfortunately, a significant temperature gradient was detected in the sample due to the heating of the container from bottom only. To decrease the temperature gradient inside the sample, only about $20 \mathrm{mg}$ of powder was placed in the crucible.

In order to improve the resolution, two decoupling pulse schemes were applied: $\mathrm{CW}$ $\left(10 \mathrm{kHz}\right.$ for ${ }^{19} \mathrm{~F} ; 5 \mathrm{kHz}$ for ${ }^{45} \mathrm{Sc}$ ) in the case of HT experiments and PISSARRO ${ }^{21}{ }^{45} \mathrm{Sc}$ and ${ }^{19} \mathrm{~F}$ in the case of MAS frequency of 30 or $60 \mathrm{kHz} .{ }^{19} \mathrm{~F},{ }^{45} \mathrm{Sc}$, and ${ }^{87} \mathrm{Rb}$ chemical shifts are referenced to $\mathrm{CFCl}_{3}, 0.11 \mathrm{M} \mathrm{ScCl}_{3}$ solution in $0.05 \mathrm{M} \mathrm{HCl}$, and $0.01 \mathrm{M} \mathrm{RbNO}_{3}$, respectively. 
The NMR parameters (chemical shifts, line widths, and quadrupolar parameters) were fitted for several different rotation frequencies and for two magnetic fields to the experimental spectra by means of the DMfit program. ${ }^{22}$ Additionally, the simulations of $1 \mathrm{D}$ and $2 \mathrm{D}$ MQMAS and RIACT ${ }^{87} \mathrm{Rb}$ spectra were performed using a fNMR package implementing the method described in Reference 23.

\section{DFT calculations}

In the case of DFT calculations using the Perdew-Burke-Ernzerhof (PBE) functional ${ }^{24}$ for compounds containing $\mathrm{Ca}, \mathrm{Sc}$, and $\mathrm{La}$ atoms, there is an overestimation of the hybridization between the $2 \mathrm{p}$ anion (oxygen or fluorine) orbitals and the unoccupied $3 \mathrm{~d}^{0}$ and $4 \mathrm{f}^{0}$ orbitals. As a consequence of this overestimation, the covalent character of a bond increases and the agreement between the experimental NMR data and theoretical predictions decreases. ${ }^{25,26}$ The DFT $+U$ method,in which the artificial energy shift $U$ of the $3 \mathrm{~d}^{0}$ states towards higher energy is inducing a decrease of bond covalency, is a suitable corrective approach on a practical level. ${ }^{25,}{ }^{26}$ The convenient value of $U$ of the DFT $+U$ method depends on the atomic species and surroundings of the atom. To determine suitable values of $U$, a series of calculations were performed using the CASTEP module ${ }^{27}$ implemented in the Materials Studio 7.0 software package. Different $U$ values were used for previously studied fluoroscandates. ${ }^{12,28}$ The correlations between calculated isotropic ${ }^{45} \mathrm{Sc}$ and ${ }^{19} \mathrm{~F}$ magnetic shielding constants $\left(\sigma_{\text {iso }}\right)$ and experimentally determined isotropic $\left(\delta_{\text {iso }}\right)$ chemical shift values has been plotted and fitted by linear regressions (Figure S1). From these fits, R-squared values were obtained. The coefficient of determination should be close to 1 . The relationship between $\mathrm{R}^{2}$ and $U$ perfectly fits with a parabolic curve with maximum at 0.051 and 0.059 Hartree for ${ }^{45} \mathrm{Sc}$ and ${ }^{19} \mathrm{~F}$ nuclei, respectively. Consequently, the value $U=0.055$ Hartree was chosen for further calculations (Figure S1).

The cut-off energies were $780 \mathrm{eV}$ and the k-point spacing of $0.04 \AA^{-1}$. The calculations were performed after a geometry optimization of all atomic positions, keeping the experimental cell parameters and symmetry constraints. The obtained relationship for ${ }^{45} \mathrm{Sc}$ and ${ }^{19} \mathrm{~F}$ at $U=0.055$ Hartree are $: \delta_{\text {iso }}=-0.8315 \times \sigma_{\text {iso }}+671.7$ and $\delta_{\text {iso }}=-0.730 \times \sigma_{\text {iso }}+70.17$, respectively.

\section{Results}

The $\mathrm{Rb}_{3} \mathrm{ScF}_{6}$ material was first checked at room temperature by $\mathrm{X}$-ray powder diffraction. The data corresponds to those reported by Turrell et al. ${ }^{14}$ Then, the phase 
transitions were analyzed by differential scanning calorimetry (DSC) method between 25 and $260{ }^{\circ} \mathrm{C}$ (Figure S2). The heating curve contains two well-separated peaks, at $\mathrm{T}_{\text {onset }}=137{ }^{\circ} \mathrm{C}$ and $\mathrm{T}_{\text {onset }}=200{ }^{\circ} \mathrm{C}$. Both thermal effects represent solid-solid phase transitions characterized by symmetrical endothermic peaks during heating and symmetrical exothermic peaks during cooling. The cooling curve shows that these individual structural modifications are transformed reversibly, at $\mathrm{T}_{\text {onset }}=202{ }^{\circ} \mathrm{C}$ and $\mathrm{T}_{\text {onset }}=145{ }^{\circ} \mathrm{C}$, respectively. The integral peak area of the thermal effects at cooling is directly proportional to the enthalpy of change during the phase transition. From that, the entropy of change of both transitions are about 0.29 $\mathrm{J} \times \mathrm{mol}^{-1} \times \mathrm{K}^{-1}$ and $0.21 \mathrm{~J} \times \mathrm{mol}^{-1} \times \mathrm{K}^{-1}$, respectively. The measured transition temperatures are slightly different from the previously reported results of Turrell et al. $\left(154\right.$ and $\left.200{ }^{\circ} \mathrm{C}\right) .{ }^{14}$ Hereafter, the three polymorph are labelled $\alpha(\mathrm{RT}), \beta$ (medium-temperature), and $\gamma(\mathrm{HT})$.

\section{Structure from Powder Diffraction}

We first investigated the structure of $\mathrm{Rb}_{3} \mathrm{ScF}_{6}$ at high temperature, as it corresponds to the highest symmetry crystal structure. At $250{ }^{\circ} \mathrm{C}$, all X-ray powder diffraction peaks of $\gamma$ $\mathrm{Rb}_{3} \mathrm{ScF}_{6}$ were indexed with a cubic cell $(F m \overline{3} m)$ which parameters $(a=9.1944(1) \AA)$ are close to the $\delta$ polymorph of $\mathrm{K}_{3} \mathrm{AlF}_{6}{ }^{2}$ Therefore this structure ( $2 \mathrm{Rb}, 1 \mathrm{Sc}$, and $1 \mathrm{~F}$ sites) was used as a starting model for Rietveld refinements (Figure 1c). The $\mathrm{K}^{+}$site was replaced by $\mathrm{Rb}^{+}$and $\mathrm{Al}^{3+}$ by $\mathrm{Sc}^{3+}$, respectively. The thermal parameters of the fluorine crystallographic site was refined anisotropically given the distortion around this anion. Rietveld refinements were stable and led to low $R$-factors (Table 1, Figure 1c). Atomic coordinates are provided in Table S1, anisotropic thermal parameters (large values, see discussion below) are presented in Table S2, and selected interatomic distances are shown in Table S3.

The powder diffraction pattern corresponding to $\beta-\mathrm{Rb}_{3} \mathrm{ScF}_{6}$ and recorded at $187{ }^{\circ} \mathrm{C}$ can be indexed with a tetragonal cell $(I 4 / m)$ and cell parameters $(a=14.4093(2) \AA$ and $c=$ 9.2015(1) $\AA$ ) close to the ones of $\beta-\mathrm{K}_{3} \mathrm{AlF}_{6}$ so that this latter structure was used as a starting model (4 Rb, $2 \mathrm{Sc}$, and $7 \mathrm{~F}$ sites). ${ }^{2}$ The Rietveld refinement was stable and led to low $R$ factors (Table 1, Figure 1b) proving that these two phases are isostructural. Coordinates of atoms and a selection of interatomic distances are shown in Table S4 and S5.

Both static or dynamic disorder influence atomic displacement parameter (ADP) values. Previously, large ADP values were observed for $\mathrm{K}_{3} \mathrm{AlF}_{6}$ and $\mathrm{Rb}_{3} \mathrm{AlF}_{6}$, and were explained by significant rotations of $\mathrm{AlF}_{6}$ octahedra. ${ }^{2,19}$ As it will be shown below from the analysis of HT NMR data, we observe the same dynamic behavior of $\mathrm{ScF}_{6}$ octahedra, which 
leads to relatively large ADP values for $\beta$ and $\gamma$ polymorphs of $\mathrm{Rb}_{3} \mathrm{ScF}_{6}$, especially for fluorine atoms.

All synchrotron powder diffraction peaks of $\alpha-\mathrm{Rb}_{3} \mathrm{ScF}_{6}$ recorded at $22{ }^{\circ} \mathrm{C}$ can be indexed with a tetragonal cell $\left(I 4_{1} / a\right)$ and cell parameters $(a=20.2561(4) \AA$ and $c=$ $36.5160(0) \AA)$ which appears isostructural to $\alpha-\mathrm{K}_{3} \mathrm{AlF}_{6}{ }^{1}$. This observation was further confirmed by electron diffraction data which showed similar patterns to $\alpha-\mathrm{K}_{3} \mathrm{AlF}_{6}$ (Figure 2 ). Due to the large number of degrees of freedom for the atomic positions $(>150)$, a joint synchrotron and neutron refinement was used to determine the structure of the $\alpha$-phase. The structure of $\alpha-\mathrm{K}_{3} \mathrm{AlF}_{6}$ was used as a starting model. During the initial steps, all sites corresponding to the same element were constrained to have the same displacement parameter and soft distance constraints were used for the $\mathrm{Sc}-\mathrm{F}$ bond length. For the final refinement, the distance constraints could be removed and each metal site was allowed its own isotropic displacement parameter while all $\mathrm{F}$ sites were constrained to have the same displacement parameter. Fourier difference maps did not show any residue in the background. The fits of the combined Rietveld refinement are shown in Figure 1a and S3. Atomic coordinates, thermal parameters, and $\mathrm{Sc}-\mathrm{F}$ and $\mathrm{Rb}-\mathrm{F}$ interatomic distances are gathered in Tables $\mathrm{S} 6$ and S7. It should also be noted that it might not be possible to synthesize good quality single crystals of $\mathrm{Rb}_{3} \mathrm{ScF}_{6}$ for precise structural elucidation, due to the inevitable crystal twinning taking place during cooling in the synthesis process. ${ }^{29}$

Additional 23 laboratory X-ray powder diffraction patterns measured at different temperatures in the range of $30-250{ }^{\circ} \mathrm{C}$ were used to obtain the thermal dependence of the cell parameters (Figure 1d). As expected, the unit cell parameters expand nearly linearly with increasing temperature. All cell parameters were transformed to pseudo cubic in order to make comparison between the different polymorphs.

Similar to the $\mathrm{K}_{3} \mathrm{AlF}_{6}$ polymorph structures described by Abakumov et al. ${ }^{1}$ and King et $a l^{2}$, the $\beta-\mathrm{Rb}_{3} \mathrm{ScF}_{6}$ structure derives from the cubic elpasolite structure of $\gamma-\mathrm{Rb}_{3} \mathrm{ScF}_{6}$ by rotation of one-fifth of the $\mathrm{ScF}_{6}$ octahedra with a $45^{\circ}$ angle around the $c$-axis. Further $45^{\circ}$ rotation of another one-fifth group of $\mathrm{ScF}_{6}$ octahedra around the $a$ or $b$-axis leads to the $\alpha$ $\mathrm{Rb}_{3} \mathrm{ScF}_{6}$ structure. This deformation of the cubic framework leads to changes in coordination environments for the rubidium atoms, while the coordination geometry around the scandium does not change and remains octahedral. In comparison with the six coordinated rubidium atoms in the $\gamma$-form (Figure 3, right), four-fifths of these atoms in the $\beta$ polymorph are in a seven coordinated pentagonal-bipyramidal environment, while the rest (one fifth) remain in 
octahedral symmetry (Figure 3, left). A further symmetry decay via rotation of another onefifth group of $\mathrm{ScF}_{6}$ octahedra results in a further increase in the coordination number of these rubidium atoms in the $\alpha$ phase: the three-fifths are in a seven coordinated and two-fifths are in an eight coordinated (a capped pentagonal bipyramid) (Figure 4, right). The geometry of the cubic twelve coordinated rubidium sites is also undergoing modifications. Whereas the coordination environment around the $\operatorname{Rb} 1(\beta)$ site remains unchanged, $\operatorname{Rb} 2(\beta)$ is eleven coordinated by $\mathrm{F}$ atoms in the form of an irregular polyhedron. Further distortion of the ideal double perovskite structure in the $\alpha$ polymorph leads to the reduction of the coordination number of the $\operatorname{Rb} 1(\beta)$ site from 12 to $9-11$ for the atoms $\mathrm{Rb} 1-7,11,14,16$. Rb10, Rb15, and Rb17 retain a 12-fold coordination.

It should be pointed out that unlike $\mathrm{K}_{3} \mathrm{AlF}_{6}$ but like $\mathrm{K}_{3} \mathrm{GaF}_{6},{ }^{30} \beta-\mathrm{Rb}_{3} \mathrm{ScF}_{6}$ transforms directly to cubic $\gamma$-phase without going through an intermediate $\gamma-\mathrm{K}_{3} \mathrm{AlF}_{6}$ with $F d d d\left(\mathrm{n}^{\circ} 70\right)$ space group. Our results are partially consistent with the former research work from Turrell et $a l .{ }^{14}$ in which isolated $\mathrm{ScF}_{6}{ }^{3-}$ octahedra were observed for all polymorphs and the cell parameter for the cubic phase was reported as $a=9.214 \AA$ at $250^{\circ} \mathrm{C}$.

It is worth noting that $\mathrm{Rb}_{3} \mathrm{ScF}_{6}$ is another new member of a small family, but expanding in recent years, of double perovskite with non-cooperative octahedral tilting (NCOT). To the best of our knowledge, this group currently includes ( $\mathrm{K}$ or $\mathrm{Rb})_{3} \mathrm{AlF}_{6}{ }^{1,2,}, 18$ $\mathrm{Sr}_{3} \mathrm{WO}_{6},{ }^{31}$ (Ba or $\left.\mathrm{Sr}\right)_{3} \mathrm{TeO}_{6},{ }^{32} \mathrm{Rb}_{2} \mathrm{~K}(\mathrm{Cr}$ or $\mathrm{Ga}) \mathrm{F}_{6},{ }^{33} \mathrm{~K}_{3} \mathrm{GaF}_{6},{ }^{30}$ (K or $\left.\mathrm{Rb}\right)_{3} \mathrm{MoO}_{3} \mathrm{~F}_{3},{ }^{34}$ $\mathrm{Rb}_{3} \mathrm{InCl}_{6},{ }^{35}$ and $\mathrm{Cs}_{1.17} \mathrm{In}_{0.81} \mathrm{Cl}_{3 .}{ }^{36}$ 

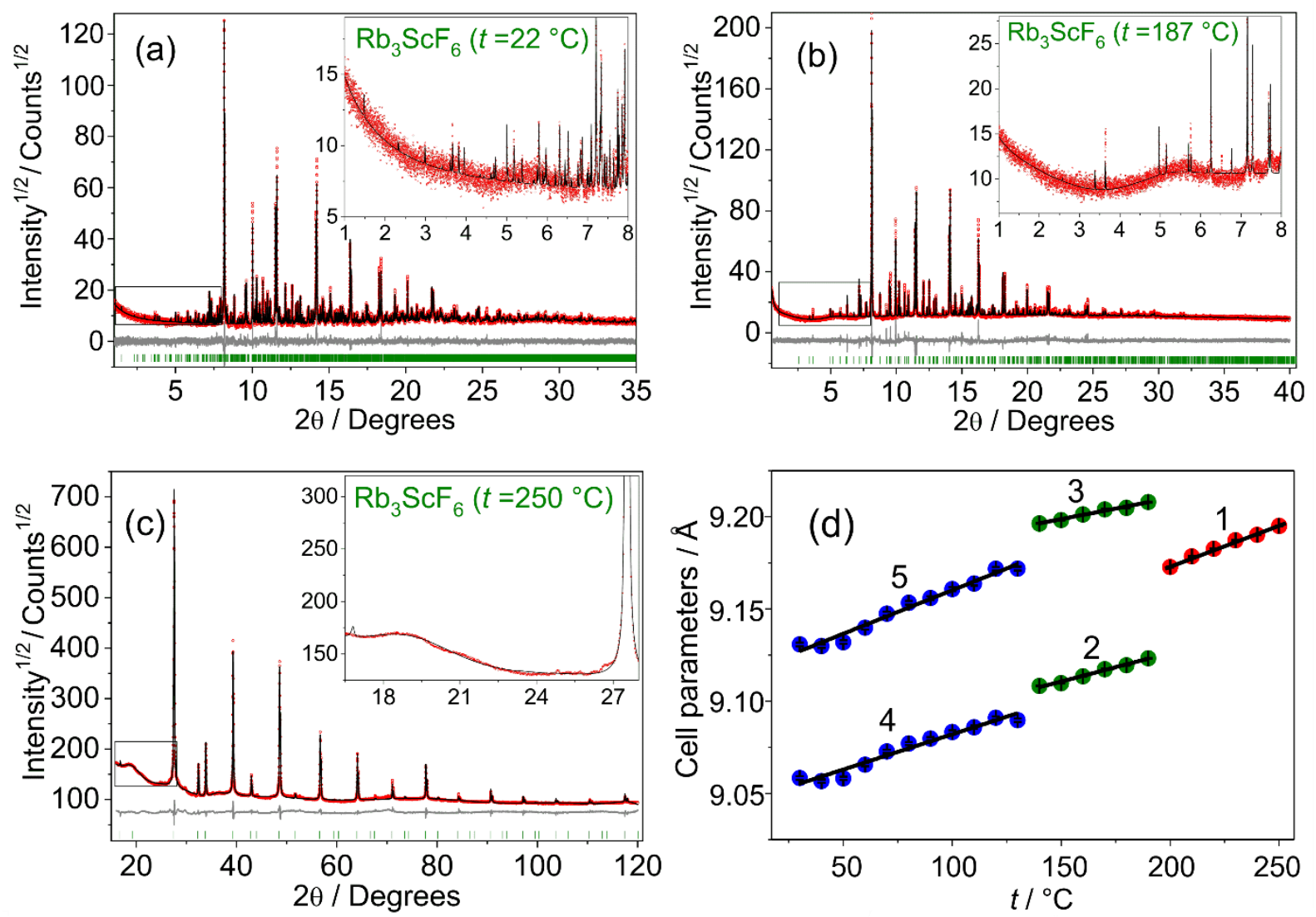

Figure 1. Rietveld refinement of synchrotron and laboratory powder X-ray diffraction patterns of $\mathrm{Rb}_{3} \mathrm{ScF}_{6}$ at: a) $22{ }^{\circ} \mathrm{C}$; b) $187{ }^{\circ} \mathrm{C}$; c) $250{ }^{\circ} \mathrm{C}$. Black dots are the observed pattern, red dots are the calculated pattern, vertical green bars are the Bragg positions, and the grey line is the difference between observed and calculated patterns. (d) Temperature dependence of the unit cell parameters of the $\alpha, \beta$, and $\gamma$ phases: $1-a$ of $\gamma$ phase $(F m \overline{3} m), 2-a / \sqrt{2} .5$ of $\beta$ phase $(I 4 / m), 3-c$ of $\beta$ phase $(I 4 / m), 4-a / \sqrt{5}$ of $\alpha$ phase $\left(I 4_{1} / a\right), 5-c / 4$ of $\alpha$ phase $\left(I 4_{1} / a\right)$.
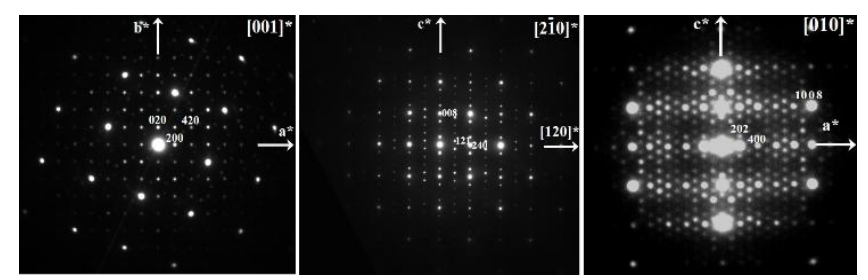

Figure 2. [001]*, [2-10]*, and [010]* selected are electron diffraction (SAED) patterns of $\alpha$ $\mathrm{Rb}_{3} \mathrm{ScF}_{6}$. The indexation corresponds to the $a=20.25 \AA$, $c=36.5 \AA$ cell with a $I 4_{1} / a$ space group. 

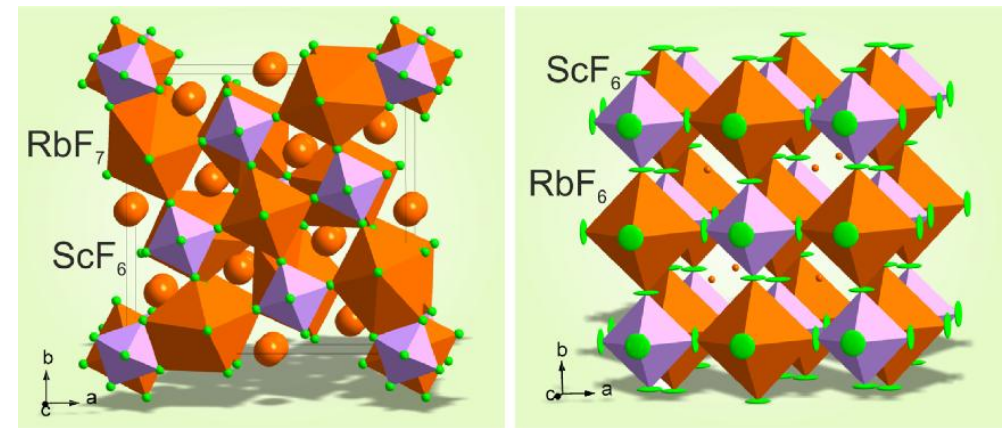

Figure 3. Crystal structure of $\mathrm{Rb}_{3} \mathrm{ScF}_{6}$ : on the left at $187^{\circ} \mathrm{C}, \beta$-phase and on the right at 250 ${ }^{\circ} \mathrm{C}, \gamma$-phase.

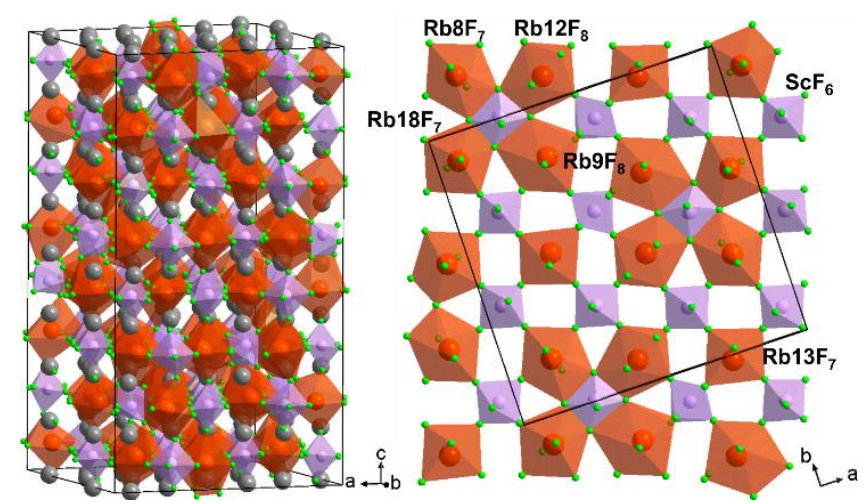

Figure 4. On the left: one unit cell of $\alpha-\mathrm{Rb}_{3} \mathrm{ScF}_{6}$. Orange $(\mathrm{Rb})$ and violet $(\mathrm{Sc})$ polyhedra form network, gray is rubidium atoms in the cavities, and green is F. On the right: Single layer of $\mathrm{Sc}$ and $\mathrm{Rb}$ coordination polyhedra viewed down the c-axis of $\alpha-\mathrm{Rb}_{3} \mathrm{ScF}_{6}$.

Table 1. Crystallographic data for the polymorphs of $\mathrm{Rb}_{3} \mathrm{ScF}_{6}$ from XRD and Neutron Rietveld refinement.

\begin{tabular}{|c|c|c|c|c|}
\hline Chemical formula & \multicolumn{2}{|c|}{$\alpha-\mathrm{Rb}_{3} \mathrm{ScF}_{6}$} & $\beta-\mathrm{Rb}_{3} \mathrm{ScF}_{6}$ & $\gamma-\mathrm{Rb}_{3} \mathrm{ScF}_{6}$ \\
\hline Source & Synchrotron & Neutron & Synchrotron & laboratory X-ray \\
\hline $\begin{array}{l}\text { Formula weight } \\
\qquad\left(\mathrm{g} \cdot \mathrm{mol}^{-1}\right)\end{array}$ & \multicolumn{2}{|c|}{415.35} & 415.35 & 415.35 \\
\hline Temperature $\left({ }^{\circ} \mathrm{C}\right)$ & 22 & 23 & 187 & 250 \\
\hline Wavelength (§̊) & 0.457893 & 1.59354 & 0.457901 & 1.5406 \\
\hline Crystal system & \multicolumn{2}{|c|}{ Tetragonal } & Tetragonal & cubic \\
\hline Space group & \multicolumn{2}{|c|}{$I 4_{1} / a(88)$} & $I 4 / m(87)$ & $F m-\overline{3} m(225)$ \\
\hline
\end{tabular}




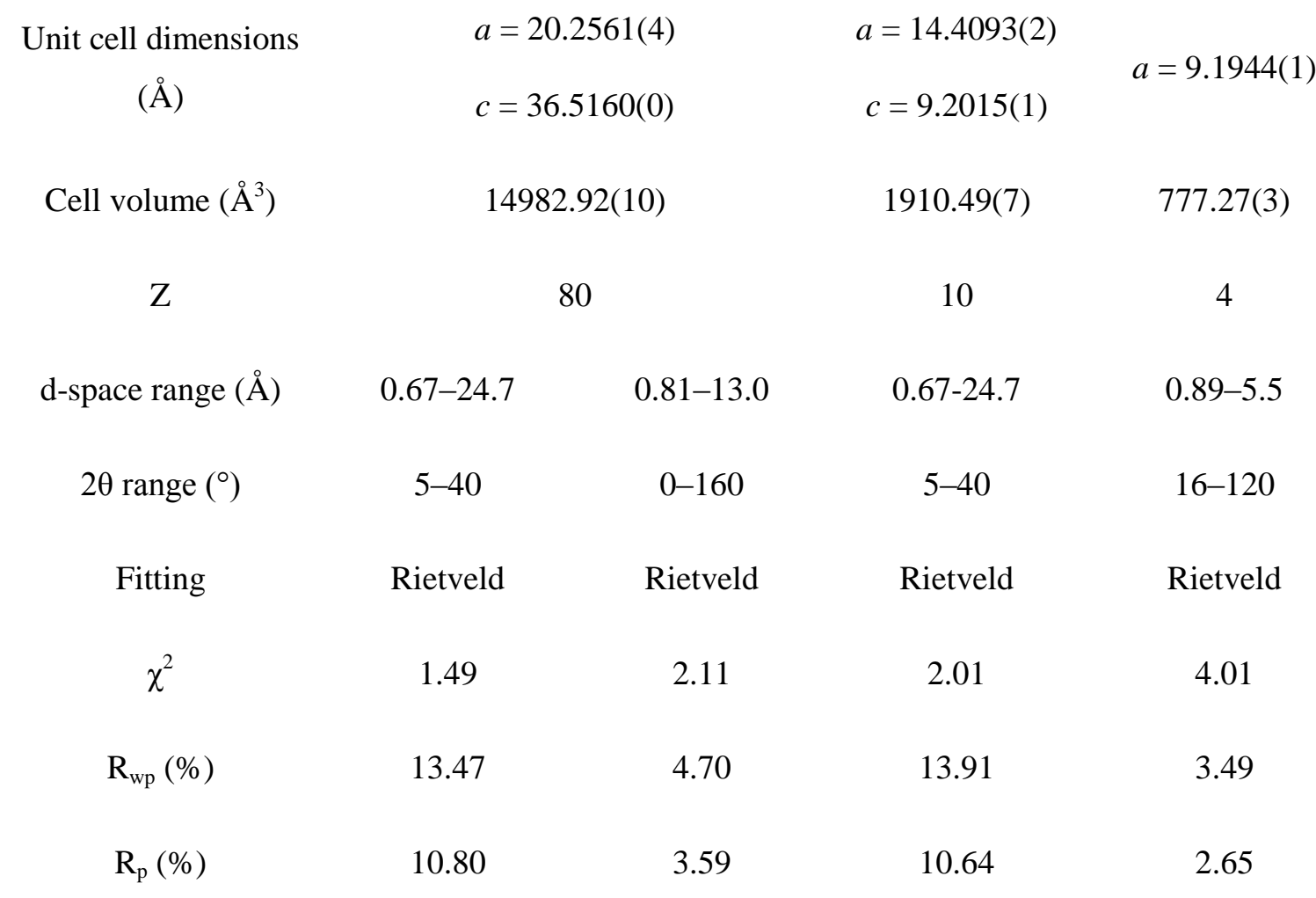

For definition of R-factors see references 15 and 16.

\section{Solid-state NMR}

From our work on powder diffraction data, the crystal structure of $\alpha-\mathrm{Rb}_{3} \mathrm{ScF}_{6}$ contains five scandium sites in octahedral environments with the same multiplicities, along with 18 rubidium and 30 fluorine sites. All fluorine atoms are terminal, i.e. non-bridging.

${ }^{45}$ Sc MAS NMR spectra recorded at $17.6 \mathrm{~T}$ and $20 \mathrm{~T}$ contain three signals (blue line Figure 5) which are reconstructed by four contributions with relative intensities 1:1:2:1 (Table 2; Figure 5 and S4). The line with higher integral intensity corresponds to two scandium sites. The ${ }^{45} \mathrm{Sc}$ chemical shift values for six and seven coordinated scandium environments range from -32 to $14 \mathrm{ppm}$ and from -67 to $-40 \mathrm{ppm}$, respectively. ${ }^{12,28}$ To the best of our knowledge, solid-state NMR data of eight coordination scandium environment were not previously reported in the literature. Therefore, from scandium NMR results, all Sc sites are six-fold coordinated. The assignment of lines to Sc sites from the integral intensities or the quadrupolar parameters cannot be provided. 


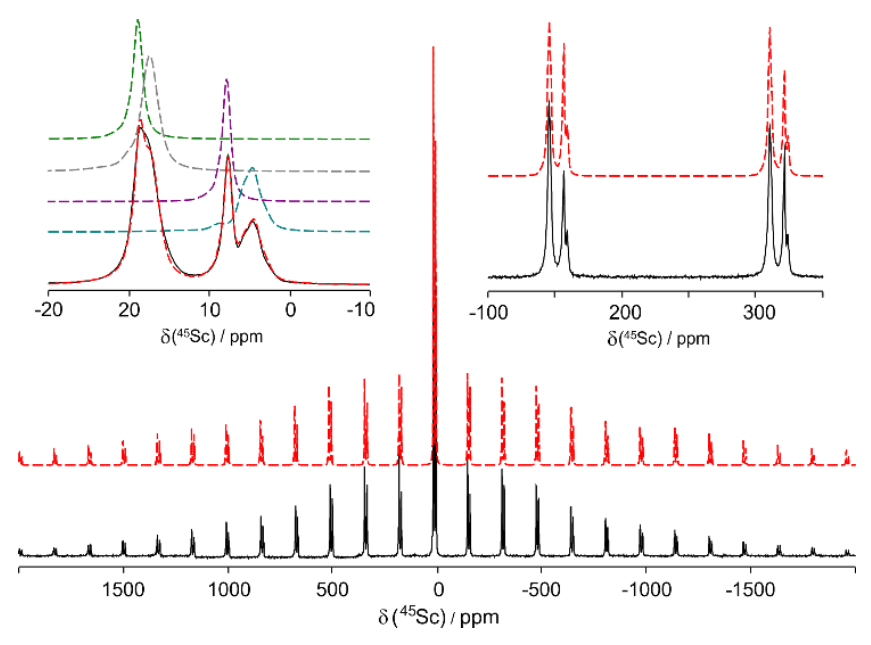

Figure 5. ${ }^{45} \mathrm{Sc}$ MAS NMR experimental (black lines) spectrum of $\alpha-\mathrm{Rb}_{3} \mathrm{ScF}_{6}$ recorded at 17.6 $\mathrm{T}$ and at $30 \mathrm{kHz}$ presented with its simulations (dashed red lines). Inserts show expanded ${ }^{45} \mathrm{Sc}$ MAS spectrum in the region of the central transition (left) and expanded satellite transition sidebands (right). Dashed color lines display the decomposition of the theoretical spectrum in its individual components.

Not surprisingly, we observed a decrease in resolution of the room temperature ${ }^{45} \mathrm{Sc}$ NMR spectrum while decreasing the MAS rotation frequency from $30 \mathrm{kHz}$ to $6 \mathrm{kHz}$, but the three ${ }^{45} \mathrm{Sc}$ peaks can still be clearly distinguished (Figure 6).

It should be emphasized that MAS raises the sample temperature due to frictional heating and that the sample temperature without temperature regulation was $31^{\circ} \mathrm{C}$ at a spinning frequency of $6 \mathrm{kHz}$ and $56^{\circ} \mathrm{C}$ at $30 \mathrm{kHz}$ instead of RT.

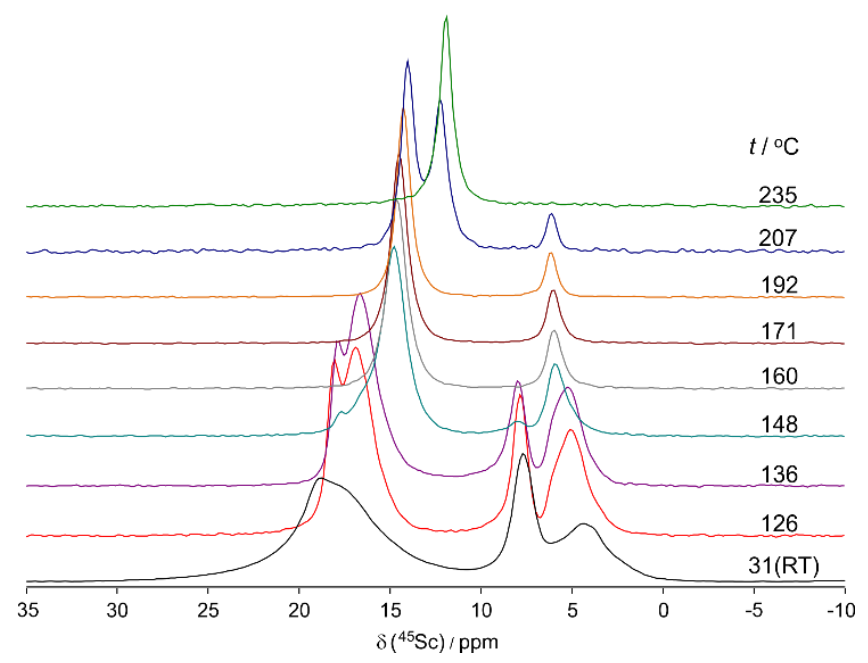

Figure 6. ${ }^{45} \mathrm{Sc} \mathrm{NMR}$ spectra of $\mathrm{Rb}_{3} \mathrm{ScF}_{6}$ acquired at $17.6 \mathrm{~T}$ and MAS $6 \mathrm{kHz}$ as a function of temperature. 
The phase transitions in $\mathrm{Rb}_{3} \mathrm{ScF}_{6}$ are clearly illustrated by the temperature evolution of the ${ }^{45} \mathrm{Sc}$ NMR spectra (Figure 6). Upon heating, the ${ }^{45} \mathrm{Sc}$ peaks sharpen notably. When reaching the $\alpha-\mathrm{Rb}_{3} \mathrm{ScF}_{6}$ to $\beta-\mathrm{Rb}_{3} \mathrm{ScF}_{6}$ phase transition temperature, the ${ }^{45} \mathrm{Sc}$ resonances further narrow and a shift is also observed. At $148{ }^{\circ} \mathrm{C}$, i.e., slightly higher than the $\alpha$ to $\beta$ phase transition temperature, the peak at around $8 \mathrm{ppm}$ has almost disappeared. As stated in the experimental part, the temperature gradient within the rotor affects the spectrum. As a result, at $148{ }^{\circ} \mathrm{C}$, the coexistence of both $\alpha$ - and $\beta$-phases was found. Above this temperature, due to the fast motion the spinning sidebands almost disappear. In the range $142-207{ }^{\circ} \mathrm{C}$, the tetragonal $\beta$-phase exists. The structure of $\beta-\mathrm{Rb}_{3} \mathrm{ScF}_{6}$ contains two Sc crystallographic sites with multiplicities of $2: 8$. The spectra recorded in this temperature range exhibit two narrow lines (FWHM of $130 \pm 20 \mathrm{~Hz}$ and $170 \pm 20 \mathrm{~Hz}$ ) with relative intensities of the signals of 1:4. The line shapes were simulated using a mixed Lorentz/Gauss function. The intense resonance at an isotropic chemical shift $\delta_{\text {iso }}$ of $14.4 \mathrm{ppm}$ is assigned to the Sc site with the multiplicity of $8(\mathrm{Sc} 2)$ and the small line at $\delta_{\text {iso }}$ of $5.9 \mathrm{ppm}$ to the Sc site with the multiplicity of 2 (Sc1) (Figure 7d). At the phase transition temperature, the coexistence of both polymorphs occurs. Above $207{ }^{\circ} \mathrm{C}$, only a singlet Lorentzian line ( $\delta_{\text {iso }}=11.9 \mathrm{ppm}, \mathrm{FWHM}=160 \mathrm{~Hz}$ at $\left.235{ }^{\circ} \mathrm{C}\right)$, corresponding to the $\gamma$-phase, is observed. Thereby, ${ }^{45} \mathrm{Sc}$ MAS NMR observations agree well with the structural models of all polymorphs. The transition temperatures correlate well with the data obtained by DSC.

Table 2. ${ }^{45} \mathrm{Sc}$ isotropic chemical shifts $\left(\delta_{\text {iso }}\right)$, quadrupolar constants $\left(\mathrm{C}_{\mathrm{Q}}\right)$, asymmetry parameters $\left(\eta_{\mathrm{Q}}\right)$, and Integral intensities (I) obtained from the simulation of the ${ }^{45} \mathrm{Sc}$ MAS at $17.6 \mathrm{~T}$ and $20 \mathrm{~T}$.

\begin{tabular}{cccc}
\hline $\begin{array}{c}\delta_{\text {iso }}, \mathrm{ppm} \\
( \pm 0.2 \mathrm{ppm})\end{array}$ & $\begin{array}{c}\mathrm{C}_{\mathrm{Q}}, \mathrm{MHz} \\
( \pm 0.1 \mathrm{MHz})\end{array}$ & $\begin{array}{c}\eta_{\mathrm{Q}} \\
( \pm 0.1)\end{array}$ & $\mathrm{I}, \%( \pm 2 \%)$ \\
\hline 19.2 & 2.3 & 0.7 & 21 \\
18.3 & 3.6 & 0.8 & 39 \\
8.1 & 2.2 & 0.95 & 18 \\
6.3 & 4.2 & 1 & 22 \\
\hline
\end{tabular}


The ${ }^{19} \mathrm{~F}$ NMR spectrum recorded at $20 \mathrm{~T}$ and $60 \mathrm{kHz}$ (see Figure S5) consists of a broad envelope of signals in the -57 to $-70 \mathrm{ppm}$ range. The complete simulation of the spectrum using Lorentzian lines revealed a minimum of 8 signals (30 are expected). It was not possible to perform an assignment of the lines to the different $\mathrm{F}$ sites.

As in the case of ${ }^{45} \mathrm{Sc} \mathrm{NMR}$, a decrease of MAS rotation frequency from $30 \mathrm{kHz}$ to 6 $\mathrm{kHz}$ induces a decrease in resolution of the ${ }^{19} \mathrm{~F}$ NMR spectrum, and upon heating up to 126 ${ }^{\circ} \mathrm{C}$, the ${ }^{19} \mathrm{~F}$ lines sharpen up (Figure S6).
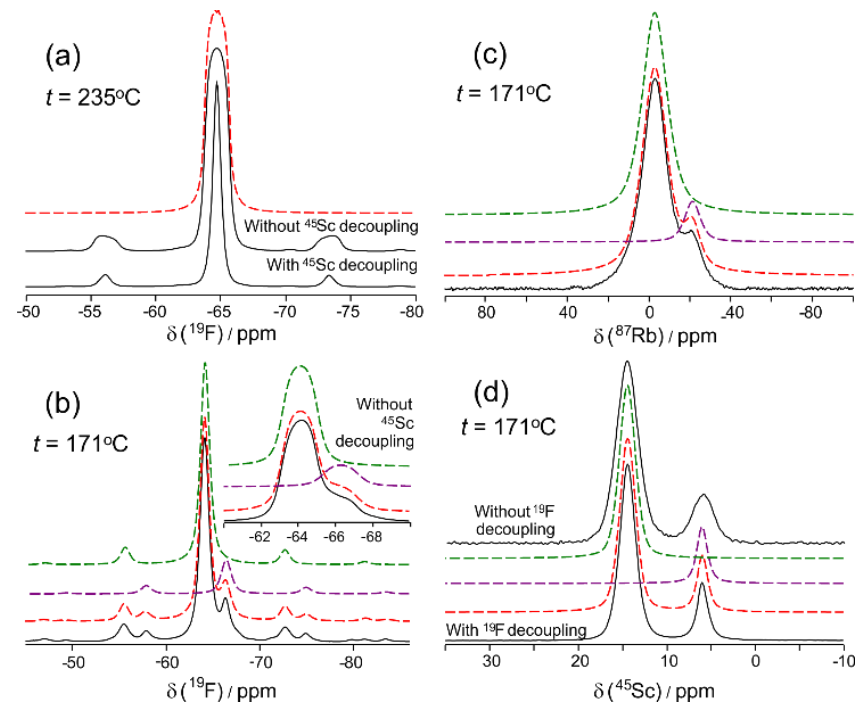

Figure 7. Experimental (black) and simulated (red) ${ }^{19} \mathrm{~F}$ (a, b), ${ }^{87} \mathrm{Rb}(\mathrm{c})$, and ${ }^{45} \mathrm{Sc}$ (d) NMR spectra at $17.6 \mathrm{~T}$ and MAS $6 \mathrm{kHz}$. (b) Insert shows ${ }^{19} \mathrm{~F}$ spectrum and its simulation without ${ }^{45} \mathrm{Sc}$ decoupling. Colored dashed curves show the decomposition of the theoretical spectrum in its individual components.

Table 3. Experimental (isotropic chemical shifts $\delta_{\text {iso, }}$ integral intensities I) and calculated (isotropic magnetic shielding $\sigma_{\text {iso }}$ and isotropic chemical shifts $\delta_{\text {calciso }}{ }^{19}$ F NMR parameters of $\beta-\mathrm{Rb}_{3} \mathrm{ScF}_{6}$.

\begin{tabular}{|c|c|c|c|c|}
\hline $\begin{array}{l}\text { Fluorine } \\
\text { site }\end{array}$ & $\sigma_{\text {iso }}, p p m$ & $\delta_{\text {calciso }}, \mathrm{ppm}$ & $<\delta_{\text {calciso }}>, \mathrm{ppm}$ & $\begin{array}{l}\delta_{\text {iso }}, \mathrm{ppm} \text { I, } \%( \pm 1 \%) \\
( \pm 0.1 \mathrm{ppm})\end{array}$ \\
\hline $\mathrm{F} 1$ & 193.61 & -71.52 & -68.1 & -66.4 \\
\hline $\mathrm{F} 2$ & 179.72 & -61.38 & $\left(\mathrm{Sc} 1 \mathrm{~F} 1_{4} \mathrm{~F} 2_{2}\right)$ & 20 \\
\hline F3 & 184.80 & -65.09 & -67.8 & -64.1 \\
\hline
\end{tabular}




\begin{tabular}{|c|c|c|}
\hline $\mathrm{F} 4$ & 193.27 & -71.28 \\
\hline F5 & 174.05 & -57.24 \\
\hline F6 & 195.68 & -73.03 \\
\hline F7 & 191.66 & -70.10 \\
\hline
\end{tabular}

Table 4. ${ }^{45} \mathrm{Sc}$ isotropic chemical shifts $\left(\delta_{\text {iso }}\right)$, and Integral intensities (I) obtained from the simulation of the ${ }^{45} \mathrm{Sc}$ MAS at 17.6 T and calculated isotropic magnetic shielding $\sigma_{\text {iso }}$ of $\beta$ and $\gamma-\mathrm{Rb}_{3} \mathrm{ScF}_{6}$.

\begin{tabular}{|c|c|c|c|c|c|}
\hline 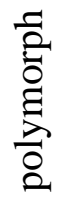 & Atom & $\begin{array}{c}\delta_{\text {iso }}, \mathrm{ppm} \\
( \pm 0.2 \mathrm{ppm})\end{array}$ & $\begin{array}{c}\mathrm{I}, \% \\
( \pm 1 \%)\end{array}$ & $\sigma_{\text {iso }}, \mathrm{ppm}$ & $\begin{array}{c}\delta_{\text {iso calc }}, \\
\text { ppm }\end{array}$ \\
\hline \multirow{2}{*}{$\beta$} & $\mathrm{Sc} 1$ & 5.9 & 20 & 799.07 & 7.23 \\
\hline & $\mathrm{Sc} 2$ & 14.4 & 80 & 788.85 & 15.73 \\
\hline$\gamma$ & $\mathrm{Sc} 1$ & 11.90 & 100 & 791.06 & 13.89 \\
\hline
\end{tabular}

After the $\alpha$ to $\beta$ phase transition, the ${ }^{19} \mathrm{~F}$ MAS NMR spectrum of $\beta-\mathrm{Rb}_{3} \mathrm{ScF}_{6}$ measured at $171{ }^{\circ} \mathrm{C}$ exhibits two peaks (Figure $7 \mathrm{~b}$ ). Accurate simulation of the spectrum, including all spinning sideband patterns, allowed to obtain the 1:4 integral intensity ratio for the resonances at $-66.4 \mathrm{ppm}$ and $-64.1 \mathrm{ppm}$ (FWHM of $910 \mathrm{~Hz}$ and $810 \mathrm{~Hz}$ ), respectively (Table 3). The discrepancy between the expected seven signals and the observed two resonances can be explained in two possible different ways. The first "classic" interpretation is that the line with low intensity corresponds to two fluorine atoms with an occupation of 4 and 8, and the second intensive line corresponds to all the remaining fluorines, i.e. four sites with an occupation of 8 and one site with an occupation of 16. In this case, the chemical shifts of two fluorines for the first peak and five fluorines for the second must be very close. Another possible explanation of the discrepancy is related to the complex dynamics of the system, such as fast hoping of the fluorine on each position around one $\mathrm{ScF}_{6}$ octahedron or, in other terms, to rotational disorder of $\mathrm{ScF}_{6}$ octahedra. In that case, ${ }^{19} \mathrm{~F} \delta_{\text {iso }}$ appears as the barycenter of the individual $\delta_{\text {iso }}$ values. The multiplicities of Sc1:Sc2 sites are 2:8, and the expected integrated intensities ratio agrees well with the experimental value. Previous works showed that this behavior is frequently observed in fluorides. ${ }^{19,37-39}$ For example, the $\gamma-\mathrm{K}_{3} \mathrm{AlF}_{6}{ }^{2}$ and $\beta-\mathrm{Rb}_{3} \mathrm{AlF}_{6}{ }^{18}$ polymorphs of the cryolite family contain eleven crystallographic inequivalent $\mathrm{F}$ sites and only four NMR lines 
can be observed in the experimental spectrum. Another example is the metastable $\mathrm{K}_{18} \mathrm{Ta}_{5} \mathrm{Zr}_{5} \mathrm{~F}_{63}$ compound, in which 7 fluorine sites and 5 signals were detected, corresponding to all five non-equivalent polyhedra. ${ }^{37}$ The dynamic of fluorine atoms in $\gamma-\mathrm{K}_{3} \mathrm{AlF}_{6}$ and $\beta$ $\mathrm{Rb}_{3} \mathrm{AlF}_{6}$ was more widely studied. ${ }^{19}$ It should also be noted that a similar rotational disorder of the $\left(\mathrm{Mo}\right.$ or $\mathrm{W} \mathrm{O}_{4}$ tetrahedra was observed in the $(\mathrm{Ca}$ or $\mathrm{Sr}$ or $\mathrm{Ba}) \mathrm{MoO}_{4}$ scheelite and $\mathrm{NaRE}\left((\mathrm{Mo} \text { or } \mathrm{W}) \mathrm{O}_{4}\right)_{2}$ scheelite-type compounds. ${ }^{40-42}$

To determine the correct explanation, we addressed GIPAW (Gauge Including Projector Augmented Waves) calculations of the NMR parameters. Figure S7 shows the ${ }^{19} \mathrm{~F}$ experimental and reconstructed spectra of $\beta-\mathrm{Rb}_{3} \mathrm{ScF}_{6}$. As evidenced from this figure, there is a large discrepancy between the two spectra. In order to calculate the ${ }^{19} \mathrm{~F}$ chemical shift values according to the second model, we averaged the calculated fluorine positions for each of the polyhedra: $\mathrm{Sc} 2 \mathrm{~F} 3 \mathrm{~F} 4 \mathrm{~F} 5 \mathrm{~F} 6 \mathrm{~F}_{2}$ and $\mathrm{Sc} 1 \mathrm{~F} 1_{4} \mathrm{~F} 2{ }_{2}$. Good overall agreement between obtained values and the experimental data was observed (Table 3). Thereby, the second assumption is acceptable and coherent with the proposed structural model and the first assumption is unlikely to take place in practice. Another confirmation of the proposed dynamic model is the absence of a quadrupole line shape in the scandium spectrum. GIPAW calculations lead to large quadrupolar constants of 13.3 and $5.9 \mathrm{MHz}$ for $\mathrm{Sc} 1$ and $\mathrm{Sc} 2$ sites, respectively. In fact, as indicated above, the ${ }^{45} \mathrm{Sc}$ MAS NMR spectrum revealed two well-defined signals with a Gaussian/Lorentzian line shape, because of faster reorientation. It should be mentioned that calculated chemical shift values fit well with those observed (Table 4).

In the case of the ${ }^{87} \mathrm{Rb}$ spectrum recorded at RT, significant signal overlap is observed resulting from the large number of $\mathrm{Rb}$ sites (18) and their quadrupolar broadening (Figure S8). To overcome these limitations, we performed 2D MQMAS NMR experiments.

Because conventional Z-filtered MQMAS experiment at $17.6 \mathrm{~T}$ was unable to provide a sufficient signal-to-noise ratio for signals with a large value of quadrupole constants (even after four days of data accumulation), we turned to RIACT excitation method. RIACT method is recognized for improving the excitation of sites undergoing large quadrupolar couplings for $\mathrm{I}=3 / 2$ nuclei, thus improving the sensitivity, at the cost of more complex line shape arising from non-uniform excitation. ${ }^{18}$ Figures 8 , S9, and S10 show RIACT and Z-filter MQMAS spectra recorded at 17.6 and $20 \mathrm{~T}$ with the same rotor. As expected, RIACT spectra demonstrate better signal-to-noise ratio. The $2 \mathrm{D}{ }^{87} \mathrm{Rb}$ RIACT NMR spectrum recorded at $20 \mathrm{~T}$ reveals six resolved peaks with large quadrupole constant ranging between 5.7 and $8.7 \mathrm{MHz}$ and eight lines close to the diagonal slope with small quadrupole splitting of the order of to 2 
MHz. The modeling of 1D spectra acquired at two different fields (17.6 and $20 \mathrm{~T}$ ) while using the NMR parameters obtained from the fits of RIACT spectra further revealed a missing intensity in the 10-30 ppm chemical shift range. Therefore, we assumed that the 1D spectra contain a supplementary line with a quadrupole constant large enough to remain undetected even when using the RIACT excitation. Figure S8 depicts the simulated 1D spectra with fourteen lines obtained from $2 \mathrm{D}$ results and one additional line with $C_{\mathrm{Q}}=11.8 \mathrm{MHz}, \eta_{\mathrm{Q}}=0.5$. It should be pointed out that the strong overlap of the ${ }^{87} \mathrm{Rb}$ resonances makes impossible to obtain unambiguous values of the integral intensities. While the NMR spectra allow to identify fifteen resolved contributions, the above described structure of $\alpha-\mathrm{Rb}_{3} \mathrm{ScF}_{6}$ features eighteen independent rubidium atomic positions. We propose to ascribe the group of high field peaks $\mathrm{Rb}$ sites with coordination number $(\mathrm{CN}) 7$ and 8; the two sets of lines with the largest $\mathrm{C}_{\mathrm{Q}}$ being ascribed to rubidium sites with $\mathrm{CN} 9-11$; and the small two $2 \mathrm{D}$ spots close to the diagonal slope can be assigned to $\mathrm{Rb}$ with $\mathrm{CN}$ 12. Thus, even though it remains impossible to perform an accurate spectral assignment of the ${ }^{87} \mathrm{Rb}$ NMR resonances with the crystallographic sites, our results allow to estimate the values of the ${ }^{87} \mathrm{Rb}$ NMR parameters and to propose line assignment.
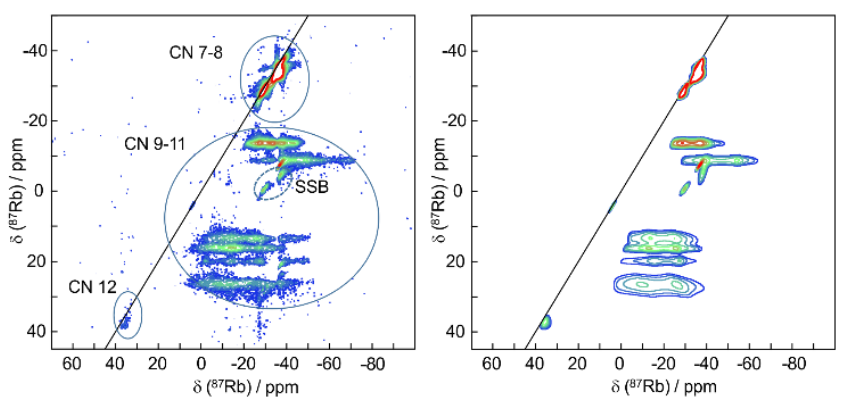

Figure 8. Experimental ${ }^{87} \mathrm{Rb}$ RIACT MQ MAS (left) NMR spectrum of $\mathrm{Rb}_{3} \mathrm{ScF}_{6}$ at $20 \mathrm{~T}$ and spinning rate of $30 \mathrm{kHz}$ and its simulation (right) with the parameters presented in Table 5.

Table 5. ${ }^{87} \mathrm{Rb}$ isotropic chemical shift $\left(\delta_{\text {iso }}\right)$, mean quadrupolar constants $\left(C_{\mathrm{Q}}\right)$, and relative intensities obtained from the simulation of the ${ }^{87} \mathrm{Rb}$ MAS and RIACT MQMAS at $17.6 \mathrm{~T}$ and $20 \mathrm{~T}$.

\begin{tabular}{ccc}
\hline$\delta_{\text {iso }}, \mathrm{ppm}$ & $C_{\mathrm{Q}}, \mathrm{MHz}$ & $\eta_{\mathrm{Q}}( \pm 0.2)$ \\
$( \pm 0.2 \mathrm{ppm})$ & $( \pm 0.4 \mathrm{MHz})$ & \\
\hline
\end{tabular}

$-21.9$

5.6

0.34 


\begin{tabular}{ccc}
-25.0 & 7.6 & 0.66 \\
-29.9 & 0.95 & 0.61 \\
-28.8 & 1.0 & 0.61 \\
-28.3 & 1.1 & 0.61 \\
-35.6 & 1.0 & 0.61 \\
-34.3 & 2.1 & 0.85 \\
-34.3 & 1.3 & 0.41 \\
-0.8 & 7.6 & 0.46 \\
1.1 & 7.3 & 0.52 \\
2.4 & 8.1 & 0.84 \\
7.3 & 8.3 & 0.01 \\
4.3 & 1.5 & 0.418 \\
36.6 & 1.8 & 0.61 \\
45.6 & 11.8 & 0.5 \\
\hline
\end{tabular}

The temperature dependence of ${ }^{87} \mathrm{Rb}$ spectra exhibits similar variations as in the cases of variable temperature ${ }^{19} \mathrm{~F}$ and ${ }^{45} \mathrm{Sc}$ NMR measurements (Figure S11). At $148{ }^{\circ} \mathrm{C}$, the spectrum contains a set of signals corresponding to $\alpha$ and $\beta$-polymorphs. The ${ }^{87} \mathrm{Rb}$ MAS NMR spectrum of $\beta-\mathrm{Rb}_{3} \mathrm{ScF}_{6}$ at $171{ }^{\circ} \mathrm{C}$ presents two resonances at -21.7 and $-2.6 \mathrm{ppm}$ with relative intensities and line widths of $13 \% / 2100 \mathrm{~Hz}$ and $87 \%$ / $3500 \mathrm{~Hz}$, respectively. According to site multiplicities, line 1 can be assigned to the Rb1 (4d) site and line 2 to the sum of all others sites (16i, 2b, 8h), respectively. ${ }^{19} \mathrm{~F}$ and ${ }^{87} \mathrm{Rb}$ NMR spectra recorded at 207 ${ }^{\circ} \mathrm{C}$ clearly indicate the phase transition from $\beta-\mathrm{Rb}_{3} \mathrm{ScF}_{6}$ to $\gamma-\mathrm{Rb}_{3} \mathrm{ScF}_{6}$. Each of the rubidium and fluorine NMR spectra was reconstructed using a single Lorentz line with a chemical shift at $2.2 \mathrm{ppm}$ and $-64.7 \mathrm{ppm}$ at $235^{\circ} \mathrm{C} ; \mathrm{FWHM}=156 \mathrm{~Hz}$ and $520 \mathrm{~Hz}$, respectively. The resulting disagreement with the presence of two rubidium sites of $4 \mathrm{~b}$ and $8 \mathrm{c}$ multiplicity in the structure can be explained by the presence of the two rubidium sites of $\gamma-\mathrm{Rb}_{3} \mathrm{ScF}_{6}$ which are involved in the chemical exchange. It should be noted that the same exchange process was observed for $\beta-\mathrm{Rb}_{3} \mathrm{AlF}_{6}{ }^{19} \mathrm{~A}$ good agreement between calculated ${ }^{19} \mathrm{~F}$ and ${ }^{45} \mathrm{Sc}$ shielding constants of $\gamma$ - 
$\mathrm{Rb}_{3} \mathrm{ScF}_{6}$ and the experimental chemical shifts was obtained (Tables 3 and 4). The temperature dependence of all NMR spectra demonstrated overall reversibility of the spectral changes.

King et al. ${ }^{2}$ observed the dynamic rotations of $\mathrm{AlF}_{6}$ octahedra in $\delta-\mathrm{K}_{3} \mathrm{AlF}_{6}$ and they proposed that "such rotations could be occurring in some of the lower temperature phases as well." We also view this dynamic as a fast hoping mechanism of the fluorine on each position around one $\mathrm{AlF}_{6}$ octahedron. ${ }^{19}$ This conjecture was confirmed by investigation of isostructural $\gamma-\mathrm{K}_{3} \mathrm{AlF}_{6}$ and $\alpha-\mathrm{Rb}_{3} \mathrm{AlF}_{6}$. In this study, we confirm this assumption for $\beta-\mathrm{Rb}_{3} \mathrm{ScF}_{6}$. Based on these findings, we revised the ${ }^{19} \mathrm{~F}$ MAS NMR spectrum of $\beta-\mathrm{K}_{3} \mathrm{AlF}_{6}$, which is isostructural with $\beta-\mathrm{Rb}_{3} \mathrm{ScF}_{6}$. It contains an asymmetrically broadened peak, which is reconstructed with two individual contributions. Unfortunately the lack of resolution of the spectrum does not allow to correctly and unequivocally measure the integrated intensity. The resulting 1:5 ratio is slightly higher than the expected one (1:4). Therefore it appears that the rotation of the $\mathrm{AlF}_{6}$ octahedra is very likely to take place in $\beta-\mathrm{K}_{3} \mathrm{AlF}_{6}$. It is worth noting that no such rotation was observed in the alpha polymorphs of $\mathrm{K}_{3} \mathrm{AlF}_{6}$ and $\mathrm{Rb}_{3} \mathrm{ScF}_{6}$. If there was a fast hoping mechanism of the fluorine on each position around one $\mathrm{AlF}_{6}$ octahedron, only five lines would be observed in the fluorine spectrum, in agreement with the number of crystallographically nonequivalent aluminium/scandium sites.

The ${ }^{19} \mathrm{~F}$ line shapes of both $\beta-\mathrm{Rb}_{3} \mathrm{ScF}_{6}$ and $\gamma-\mathrm{Rb}_{3} \mathrm{ScF}_{6}$ spectra recorded without scandium decoupling can be ascribed as non-resolved multiplets (Figures $7 \mathrm{a}$ and $7 \mathrm{~b}$ ). From the fitted spectrum, the coupling constant values are ${ }^{1} J\left({ }^{45} \mathrm{Sc},{ }^{19} \mathrm{~F}\right) 164,167 \mathrm{~Hz}$ for $\beta$ - and 160 $\mathrm{Hz}$ for $\gamma$-phases. These values are in good agreement with previous results obtained for fluoroscandates. ${ }^{28,43}$

\section{Conclusions}

In this work, the interplay between X-ray and neutron powder diffraction, solid state NMR, SAED, and theoretical calculations is exploited in order to achieve an accurate description of the structure of the three $\alpha-, \beta-$, and $\gamma-\mathrm{Rb}_{3} \mathrm{ScF}_{6}$ polymorphs. The structures, two tetragonal and one cubic forms, were determined from X-ray and neutron powder diffraction structural analysis based on isostructural $\mathrm{K}_{3} \mathrm{AlF}_{6}$ models and these were further confirmed by solid state NMR and SAED methods. The structural correlation between the three polymorphs was also discussed. Two new examples of non-cooperative octahedral tilting are reported. High temperature MAS NMR appears as a powerful method that enables in-situ monitoring of the local dynamics of $\mathrm{ScF}_{6}$ octahedra and phase transitions. A good agreement was achieved for 
observed and calculated NMR parameters. We expect this work to stimulate future opportunities in the synthesis and the investigation of $\mathrm{Mn}^{4+}$ or lanthanide doped $\mathrm{Rb}_{3} \mathrm{ScF}_{6}$ with interesting optical properties.

\section{ACKNOWLEDGMENT}

For DFT calculations, we thank the "Centre de Calcul Scientifique en region Centre" (Orléans, France). We acknowledge the ICMN (Orléans, France) for access to their Transmission Electron Microscope. Financial support from the IR-RMN-THC Fr3050 CNRS for conducting the research is gratefully acknowledged. This study was also financially supported by VEGA-2/0060/18 and ITMS project (code 313021T081, Research \& Innovation Operational Programme funded by the ERDF). We thank also Dr. F.Vivet, Dr. F.Fayon, and Dr. D.Massiot for useful discussions.

\section{ASSOCIATED CONTENT}

\section{Supporting Information}

Tables of atomic coordinates and atomic displacement parameters; tables of bond distances; $R^{2}(U)$ and $\delta_{\text {iso }}\left(\sigma_{\text {iso }}\right)$; DSC; Neutron diffraction data; ${ }^{45} \mathrm{Sc},{ }^{19} \mathrm{~F}$, and ${ }^{87} \mathrm{Rb}$ MAS NMR; ${ }^{87} \mathrm{Rb} \mathrm{Z}-$ filter and RIACT MQMAS (PDF); Crystallographic data (CIF). The Supporting Information is available free of charge on the ACS Publications website.

The crystallographic data are deposited in Cambridge Crystallographic Data Centre (CSD \# 2062818, 2027066, and 2027067). The data can be downloaded from the site (www.ccdc.cam.ac.uk/data_request/cif).

\section{AUTHOR INFORMATION}

\section{Corresponding Authors}

* Aydar Rakhmatullin, e-mail: rakhmat@cnrs-orleans.fr, tel.: 0033-238255512

\section{Author Contributions}

A.R. conceptualized and planned the project. F.S. performed the DSC experiments. M.M., G.K., and M.A. performed structural analysis. M.A. performed high temperature XRD experiments. ES performed neutron experiment. A.R. conducted of the all NMR experiments with assistance from E.C. and C.B. I.B.P., R.B., and K.V.M. performed the synthesis 
experiments. A.R. carried out the CASTEP calculations. The manuscript was written with contribution from all co-authors.

\section{Notes}

The authors declare no competing financial interest.

\section{REFERENCES}

1. Abakumov, A. M.; King, G.; Laurinavichute, V. K.; Rozova, M. G.; Woodward, P. M.; Antipov, E. V., The Crystal Structure of $\alpha-\mathrm{K}_{3} \mathrm{AlF}_{6}$ : Elpasolites and Double Perovskites with Broken Corner-Sharing Connectivity of the Octahedral Framework. Inorg. Chem. 2009, 48 (19), 9336-9344.

2. King, G.; Abakumov, A. M.; Woodward, P. M.; Llobet, A.; Tsirlin, A. A.; Batuk, D.; Antipov, E. V., The High-Temperature Polymorphs of $\mathrm{K}_{3} \mathrm{AlF}_{6}$. Inorg. Chem. 2011, 50 (16), 7792-7801.

3. Ai, Y.; Tu, D.; Zheng, W.; Liu, Y.; Kong, J.; Hu, P.; Chen, Z.; Huang, M.; Chen, X., Lanthanide-doped $\mathrm{NaScF}_{4}$ nanoprobes: crystal structure, optical spectroscopy and biodetection. Nanoscale 2013, 5 (14), 6430-6438.

4. Yu, B.; Hao, E.; Fang, S.; Liu, Z.; Wang, Y.; Lv, Z.; Li, N.; Zhang, X.; Shi, L.; Du, Y., Controlled synthesis of high quality scandium-based nanocrystals as promising recyclable catalysts for silylcyanation reaction. Nanoscale 2017, 9 (31), 10987-10991.

5. Xiong, J.; Yu, J.; Zhang, Y.; Xia, W.; Hu, S.; Zhang, Y.; Yang, J., One-step surfactantfree synthesis of $\mathrm{KSc}_{2} \mathrm{~F}_{7}$ microcrystals: controllable phases, rich morphologies and multicolor down conversion luminescence properties. CrystEngComm 2018, 20 (28), 3978-3986.

6. Zhang, L.; Zhao, S.; Liang, Z.; Zhang, J.; Zhu, W.; Liu, P.; Sun, H., The colour tuning of upconversion emission from green to red in $\mathrm{NaScF}_{4}: \mathrm{Yb}^{3+} / \mathrm{Er}^{3+}$ nanocrystals by adjusting the reaction time. J. Alloys Compd. 2017, 699, 1-6.

7. Tyagi, A. K.; Köhler, J.; Balog, P.; Weber, J., Syntheses and structures of $\mathrm{Li}_{3} \mathrm{ScF}_{6}$ and high pressure $\mathrm{LiScF}_{4}$, luminescence properties of $\mathrm{LiScF}_{4}$, a new phase in the system $\mathrm{LiF}$ $\mathrm{ScF}_{3}$. J. Solid State Chem. 2005, 178 (9), 2620-2625.

8. Chen, D.; Peng, Y.; Li, X.; Zhong, J.; Huang, H.; Chen, J., Simultaneous Tailoring of Dual-Phase Fluoride Precipitation and Dopant Distribution in Glass to Control Upconverting Luminescence. ACS Appl. Mater. Interfaces 2019, 11 (33), 30053-30064.

9. Ming, H.; Liu, S.; Liu, L.; Peng, J.; Fu, J.; Du, F.; Ye, X., Highly Regular, Uniform $\mathrm{K}_{3} \mathrm{ScF}_{6}: \mathrm{Mn}^{4+}$ Phosphors: Facile Synthesis, Microstructures, Photoluminescence Properties, 
and Application in Light-Emitting Diode Devices. ACS Appl. Mater. Interfaces 2018, 10 (23), 19783-19795.

10. Song, E.; Wang, J.; Shi, J.; Deng, T.; Ye, S.; Peng, M.; Wang, J.; Wondraczek, L.;

Zhang, Q., Highly Efficient and Thermally Stable $\mathrm{K}_{3} \mathrm{AlF}_{6}: \mathrm{Mn}^{4+}$ as a Red Phosphor for UltraHigh-Performance Warm White Light-Emitting Diodes. ACS Appl. Mater. Interfaces 2017, 9 (10), 8805-8812.

11. Krylov, A. S.; Molokeev, M. S.; Misyul, S. V.; Krylova, S. N.; Oreshonkov, A. S.; Ivanenko, A. A.; Zykova, V. A.; Ivanov, Y. N.; Sukhovsky, A. A.; Voronov, V. N.; Safonov, I. N.; Vtyurin, A. N., Crystal structure and phase transitions of a layered perovskite-like $\mathrm{CsScF}_{4}$ crystal. CrystEngComm 2016, 18 (43), 8472-8486.

12. Rakhmatullin, A.; Allix, M.; Polovov, I. B.; Maltsev, D.; Chukin, A. V.; Bakirov, R.; Bessada, C., Combining solid state NMR, powder X-ray diffraction, and DFT calculations for $\mathrm{CsSc}_{3} \mathrm{~F}_{10}$ structure determination. J. Alloys Compd. 2019, 787, 1349-1355.

13. Yin, Y. New Solid-State Fluorides: Synthesis, Crystal Chemistry, and Optical Properties. Ph.D, Oregon State University, Oregon, USA, 1993.

14. Turrell, S.; Hafsi, S.; Conflant, P.; Barbier, P.; Drache, M.; Champarnaud-Mesjard, J. C., Vibrational spectra, phase transitions and force-fields in crystalline scandium hexafluorides. J. Mol. Struct. 1988, 174, 449-454.

15. Bruker; AXS, TOPAS 4.2. In User's Manual. General profile and structure analysis software for powder diffraction data, Karlsruhe, Germany, 2009.

16. Petrř́ček, V.; Dušek, M.; Palatinus, L. Crystallographic Computing System JANA2006: General features. Z. Kristallogr. 2014, 229, 345-352.

17. Massiot, D., Sensitivity and Lineshape Improvements of MQ-MAS by RotorSynchronized Data Acquisition. J. Magn. Reson., Series A 1996, 122 (2), 240-244.

18. Wu, G.; Rovnyak, D.; Griffin, R. G., Quantitative Multiple-Quantum Magic-AngleSpinning NMR Spectroscopy of Quadrupolar Nuclei in Solids. J. Am. Chem. Soc. 1996, 118 (39), 9326-9332.

19. Rakhmatullin, A.; Šimko, F.; Véron, E.; Allix, M.; Martineau-Corcos, C.; Fitch, A.; Fayon, F.; Shakhovoy, R. A.; Okhotnikov, K.; Sarou-Kanian, V.; Korenko, M.; Netriová, Z.; Polovov, I. B.; Bessada, C., X-ray Diffraction, NMR Studies, and DFT Calculations of the Room and High Temperature Structures of Rubidium Cryolite, $\mathrm{Rb}_{3} \mathrm{AlF}_{6}$. Inorg. Chem. 2020, 59 (9), 6308-6318. 
20. Angeli, F.; Charpentier, T.; De Ligny, D.; Cailleteau, C., Boron Speciation in SodaLime Borosilicate Glasses Containing Zirconium. J. Am. Ceram. Soc. 2010, 93 (9), 26932704.

21. Weingarth, M.; Bodenhausen, G.; Tekely, P., Probing the quenching of rotary resonance by PISSARRO decoupling. Chem. Phys. Lett. 2011, 502 (4-6), 259-265.

22. Massiot, D.; Fayon, F.; Capron, M.; King, I.; Le Calvé, S.; Alonso, B.; Durand, J. O.; Bujoli, B.; Gan, Z.; Hoatson, G., Modelling one and two-dimensional solid-state NMR spectra. Magn. Reson. Chem. 2002, 40 (1), 70-76.

23. Charpentier, T.; Fermon, C.; Virlet, J., Numerical and theoretical analysis of multiquantum magic-angle spinning experiments. J. Chem. Phys. 1998, 109 (8), 3116-3130. 24. Perdew, J. P.; Burke, K.; Ernzerhof, M., Generalized Gradient Approximation Made Simple. Phys. Rev. Lett. 1996, 77 (18), 3865-3868.

25. Profeta, M.; Benoit, M.; Mauri, F.; Pickard, C. J., First-Principles Calculation of the ${ }^{17} \mathrm{O}$ NMR Parameters in Ca Oxide and Ca Aluminosilicates: the Partially Covalent Nature of the $\mathrm{Ca}-\mathrm{O}$ Bond, a Challenge for Density Functional Theory. J. Am. Chem. Soc. 2004, 126 (39), 12628-12635.

26. Sadoc, A.; Body, M.; Legein, C.; Biswal, M.; Fayon, F.; Rocquefelte, X.; Boucher, F., NMR parameters in alkali, alkaline earth and rare earth fluorides from first principle calculations. Phys. Chem. Chem. Phys. 2011, 13 (41), 18539-18550.

27. Clark Stewart, J.; Segall Matthew, D.; Pickard Chris, J.; Hasnip Phil, J.; Probert Matt, I. J.; Refson, K.; Payne Mike, C., First principles methods using CASTEP. Z. Kristallogr. 2005, 220 (5/6), 567-570.

28. Rakhmatullin, A.; Polovov, I. B.; Maltsev, D.; Allix, M.; Volkovich, V.; Chukin, A. V.; Boča, M.; Bessada, C., Combined Approach for the Structural Characterization of Alkali Fluoroscandates: Solid-State NMR, Powder X-ray Diffraction, and Density Functional Theory Calculations. Inorg. Chem. 2018, 57 (3), 1184-1195.

29. Abakumov, A. M.; Rossell, M. D.; Alekseeva, A. M.; Vassiliev, S. Y.; Mudrezova, S. N.; Van Tendeloo, G.; Antipov, E. V., Phase transitions in $\mathrm{K}_{3} \mathrm{AlF}_{6}$. J. Solid State Chem. 2006, $179(2), 421-428$.

30. King, G., New examples of non-cooperative octahedral tilting in a double perovskite: phase transitions in $\mathrm{K}_{3} \mathrm{GaF}_{6}$. Acta Crystallogr. Sect. B 2020, 76 (5).

31. King, G.; Abakumov, A. M.; Hadermann, J.; Alekseeva, A. M.; Rozova, M. G.; Perkisas, T.; Woodward, P. M.; Van Tendeloo, G.; Antipov, E. V., Crystal Structure and Phase Transitions in $\mathrm{Sr}_{3} \mathrm{WO}_{6}$. Inorg. Chem. 2010, 49 (13), 6058-6065. 
32. Stöger, B.; Weil, M.; Zobetz, E., $\mathrm{Sr}_{3} \mathrm{TeO}_{6}$ and $\mathrm{Ba}_{3} \mathrm{TeO}_{6}$ : double perovskites with pronounced superstructures. Z. Kristallogr. - Crystalline Materials 2010, 225 (4), 125. 33. Javier Zúñiga, F.; Tressaud, A.; Darriet, J., The low-temperature form of $\mathrm{Rb}_{2} \mathrm{KCrF}_{6}$ and $\mathrm{Rb}_{2} \mathrm{KGaF}_{6}$ : The first example of an elpasolite-derived structure with pentagonal bipyramid in the B-sublattice. J. Solid State Chem. 2006, 179 (12), 3607-3614.

34. Fry, A. M.; Woodward, P. M., Structures of $\alpha-\mathrm{K}_{3} \mathrm{MoO}_{3} \mathrm{~F}_{3}$ and $\alpha-\mathrm{Rb}_{3} \mathrm{MoO}_{3} \mathrm{~F}_{3}$ :

Ferroelectricity from Anion Ordering and Noncooperative Octahedral Tilting. Cryst. Growth Des. 2013, 13 (12), 5404-5410.

35. Majher, J. D.; Gray, M. B.; Liu, T.; Holzapfel, N. P.; Woodward, P. M., $\mathrm{Rb}_{3} \mathrm{InCl}_{6}$ : A Monoclinic Double Perovskite Derivative with Bright $\mathrm{Sb}^{3+}$-Activated Photoluminescence. Inorg. Chem. 2020.

36. Tan, X.; Stephens, P. W.; Hendrickx, M.; Hadermann, J.; Segre, C. U.; Croft, M.; Kang, C.-J.; Deng, Z.; Lapidus, S. H.; Kim, S. W.; Jin, C.; Kotliar, G.; Greenblatt, M., Tetragonal $\mathrm{Cs}_{1.17} \mathrm{In}_{0.81} \mathrm{Cl}_{3}$ : A Charge-Ordered Indium Halide Perovskite Derivative. Chem. Mater. 2019, 31 (6), 1981-1989.

37. Boča, M.; Molokeev, M. S.; Rakhmatullin, A.; Kubíková, B.; Netriová, Z., The structure of the metastable $\mathrm{K}_{18} \mathrm{Ta}_{5} \mathrm{Zr}_{5} \mathrm{~F}_{63}$ phase. New J. Chem. 2020, 44 (22), 9264-9270. 38. Smrčok, L.; Le Bail, A.; Boča, M.; Rakhmatullin, A., Polymorphism of $\mathrm{K}_{2} \mathrm{ZrF}_{6}$. Cryst. Growth Des. 2020, 20 (6), 3867-3881.

39. Boča, M.; Rakhmatullin, A.; Mlynáriková, J.; Hadzimová, E.; Vasková, Z.; Mičušík, M., Differences in XPS and solid state NMR spectral data and thermo-chemical properties of iso-structural compounds in the series $\mathrm{KTaF}_{6}, \mathrm{~K}_{2} \mathrm{TaF}_{7}$ and $\mathrm{K}_{3} \mathrm{TaF}_{8}$ and $\mathrm{KNbF}_{6}, \mathrm{~K}_{2} \mathrm{NbF}_{7}$ and $\mathrm{K}_{3} \mathrm{NbF}_{8}$. Dalton Trans. 2015, 44 (39), 17106-17117.

40. Rabuffetti, F. A.; Culver, S. P.; Suescun, L.; Brutchey, R. L., Structural Disorder in $\mathrm{AMoO}_{4}(\mathrm{~A}=\mathrm{Ca}, \mathrm{Sr}, \mathrm{Ba})$ Scheelite Nanocrystals. Inorg. Chem. 2014, 53 (2), 1056-1061.

41. Culver, S. P.; Brutchey, R. L., Thermally activated rotational disorder in $\mathrm{CaMoO}_{4}$ nanocrystals. CrystEngComm 2016, 18 (24), 4485-4488.

42. Amarasinghe, D. K.; Perera, S. S.; Rabuffetti, F. A., Rotational Disorder in ScheeliteType $\mathrm{NaRE}\left(\mathrm{MO}_{4}\right)_{2}(\mathrm{RE}=$ Rare-Earth, Y; M = Mo, W). Cryst. Growth Des. 2020, 20 (5), 3442-3448.

43. Pfadenhauer, E. H.; McCain, D. C., Nuclear magnetic resonance of fluoroscandate anion, $\mathrm{ScF}_{6}{ }^{3-}$, in aqueous solution. J. Phys. Chem. 1970, 74 (17), 3291-3293. 


\section{For Table of Contents Only}

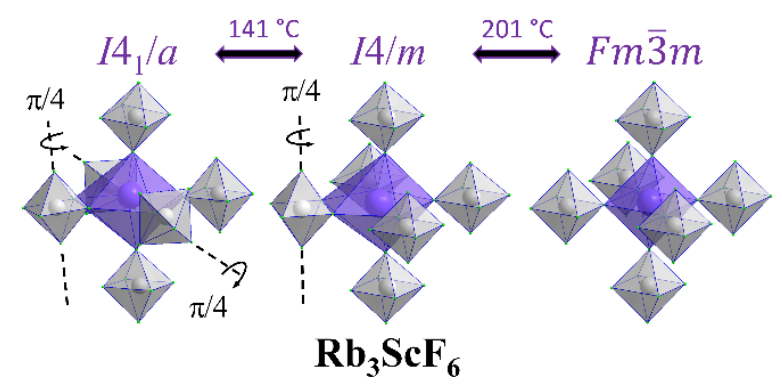

Synopsis: Structure of the three $\alpha-, \beta-$, and $\gamma-\mathrm{Rb}_{3} \mathrm{ScF}_{6}$ polymorphs with noncooperative octahedral tilting were solved and investigated using a combination of synchrotron, laboratory, and neutron powder diffraction, high temperature solid-state NMR, electron diffraction, and first-principles calculations. Dynamic rotations of $\mathrm{ScF}_{6}$ units are observed and discussed. 